\title{
Implementation of Radio Frequency Identification for Medication Tray Management
}

\author{
Edith Rolko and Thomas Chan
}

\section{INTRODUCTION}

$\mathrm{P}$ harmacy departments in hospitals continue to be pressured to increase both productivity and patient safety with limited resources. Utilizing technology and ensuring full scope of practice for pharmacy technicians will help to meet these objectives. One area of the pharmacy distribution process that has remained largely manual is replenishment of medication trays for both the operating room (OR) and resuscitation carts. This fully manual process is time-consuming and prone to human error that can result in harm to patients and increased costs of care. ${ }^{1-3}$ Previous studies have shown that errors related to drug administration are particularly troublesome in the $\mathrm{OR}$, where the consequences can be devastating for the patient. ${ }^{4}$

North York General Hospital is a 420-bed community academic hospital providing a full range of clinical services in Toronto, Ontario. More than 31400 inpatient and outpatient surgeries are performed at the hospital annually, with 110000 visits to the emergency department and 5800 obstetric deliveries.

At the time this study was undertaken, the hospital had a select group of registered pharmacy technicians who were trained and certified to manage medication tray inventory and replenishment for the OR and resuscitation carts. Each tray was prepared and checked by a registered pharmacy technician, who used the following steps to ensure accuracy in the stocked medications: (1) perform visual check to identify used or open medications and to ensure that each medication was in the proper pocket location in the tray; (2) check par levels to ensure that the correct quantity of each drug was present; (3) check expiry dates of products; (4) replenish the tray with unopened, non-expired and correct medications; (5) conduct final verification; and (6) complete documentation. Medication tray maintenance was a time-consuming, tedious task and involved the processing of 20 to 30 trays by one technician each day. The requirement that only select pharmacy technicians, with appropriate certification, could perform the task limited staffing flexibility and responsiveness in the event of an urgent tray request.

Only the resuscitation trays were double-checked by another technician; OR trays were not independently double-checked by a different technician. In any manual replenishment process, human error remains a factor, even with a rigorous certification process in place and even if the most experienced of technicians perform the task. If errors are not caught before the trays leave the pharmacy, they might be identified by other health care professionals, but they might also go undetected. Incomplete or incorrect trays can potentially result in serious consequences for patients. Recognizing that tray errors are not acceptable in the provision of quality patient care, the hospital began to explore an automated solution to eliminate such risks without additional staffing.

The hospital implemented bar codes for medication administration at the bedside in 2010, and all items dispensed by the pharmacy now have a bar code. Therefore, utilization of this technology was reviewed as a first potential option for automation of tray management. From a workflow perspective, it was determined that the use of bar-code scanning would not be effective for replenishing and checking medication trays, because each bar code must be individually scanned to ensure that the correct product has been dispensed. Medication trays may contain more than 100 items, and scanning would be tedious and time-consuming. In addition, most bar codes do not include the lot number and expiry date, so this critical information would still require manual checking by a technician.

Given these limitations of bar codes, the use of radio frequency identification (RFID) technology was considered next. An RFID system uses tags that can be encoded with electronically stored information, such as drug name, lot number, and expiry date; each tag can then be affixed to the appropriate medication container. The RFID tag is small and does not interfere with visibility of the vendor label on the drug container. All RFIDtagged items in a medication trays can be scanned at one time, which can significantly reduce the time required to confirm accuracy of replenishment.

In October 2014, the hospital deployed the Intelliguard Kit and Tray Management System (MEPS Real-Time, Inc, Carlsbad, California) as an automated solution for tray replenishment. This system uses RFID technology that is suitable for medication tray replenishment. It allows customization of trays, 
such that multiple tray types can be prepared and checked, with each tray type containing different medications in different quantities. For example, OR trays and resuscitation trays must hold completely different items in different quantities. Once an RFID tag has been affixed to each medication item, it is encoded with the drug name, lot number, and expiry date. An entire lot of medication can be encoded at the same time and can then be used for restocking any type of medication tray. The system scans and compares the medications placed in the tray with the corresponding tray type, and then determines whether items, quantities, and expiry dates are accurate before the tray is approved for use.

At the study hospital, the affixing and encoding of RFID tags is performed by the "bar-coding" pharmacy technician, who was originally dedicated to affixing bar codes on medication containers for scanning and administration at the bedside. The existing bar-coding position absorbed the workload associated with RFID tagging and encoding, with no additional staff required. The increased efficiency enabled by use of the RFID technology has eliminated the tedious manual tray-checking process, allowing technicians to focus on other value-added professional activities.

The hospital and its satellite pharmacy at another site converted 7 medication tray types, accounting for a total of more than $150 \mathrm{OR}$ and resuscitation trays (Table 1 ) to the automated RFID system.

The primary goal of implementing the RFID system was to process medication trays safely and accurately. An added benefit of what was primarily intended as a patient safety initiative was a saving in the time required for tray replenishment.

In November 2014 (1 month after implementation), the vendor and the hospital conducted a quality improvement study to validate the impact of the automated RFID system, relative to manual replenishment, on both accuracy of tray management and time required.

\section{METHODS}

\section{Study Design}

The study was designed to collect data on inventory accuracy and time for tray replenishment. Inventory accuracy was measured upon completion of tray replenishment by each technician, either manually or with the automated process. The time required to perform the restocking tasks, from start to finish, was also recorded.

Four pharmacy technicians participated in the study. Each participant was asked to restock 4 different tray types. Errors were planted in each tray by the vendor employee, without the technician's knowledge, before replenishment was performed. Each participant was informed that errors had been planted in the trays but not the exact number or type of errors. The tray types used in the study (both medium and extra-large sizes) are listed in Table 2 . The total number of study tray runs under each system was 16 ( 4 technicians $\times 4$ trays).
Table 3 shows the error types planted and their coding. Table 4 lists, for each tray type, the drug(s) planted in error, along with the error types. For each tray type, identical errors were planted for all 4 technicians and for both the manual and automated runs.

\section{Manual Replenishment Workflow}

Each pharmacy technician first restocked each of the 4 tray types using the standard manual process. The technicians used the 6 established steps for manual verification, as outlined in the Introduction. After each technician had completed manual replenishment for the 4 tray types, a vendor employee recorded the errors missed by the technician (if any) and the time required for each tray, and then reset all of the tray errors for the next technician.

\section{Automated Workflow}

Each pharmacy technician was then asked to restock each of the 4 tray types using the automated system, according to the following 5 steps: (1) perform visual check to identify used or open medications and to ensure that each medication was in the proper pocket location in the tray; (2) scan tray to automatically compare medication inventory against tray specifications;

\section{Table 1. OR and Resuscitation Tray Types That Were Converted to the Automated RFID system}

\begin{tabular}{lcc} 
Tray Type & $\begin{array}{c}\text { No. of } \\
\text { Trays }\end{array}$ & $\begin{array}{c}\text { Items per } \\
\text { Tray }\end{array}$ \\
\hline Anesthesia OR & 28 & 138 \\
General anesthesia, Branson location & 51 & 76 \\
Labour and delivery & 61 & 38 \\
Resuscitation C (adult) & 42 & 25 \\
Resuscitation D (adult) & 42 & 78 \\
Resuscitation P (pediatrics) & 20 & 47 \\
Endoscopy & 81 & 26 \\
\hline OR = operating room, RFID = radio frequency identification.
\end{tabular}

Table 2. Categorization of Tray Types Used in the Study by Number of Items

\begin{tabular}{ll} 
Tray Category & \multicolumn{1}{c}{ Tray Type } \\
\hline Medium (21-50 items) & $\begin{array}{l}\text { Resuscitation C (adult) } \\
\text { Resuscitation P (pediat } \\
\text { Extra-large ( } \geq 76 \text { items) } \\
\text { Anesthesia OR } \\
\text { Resuscitation D (adult) }\end{array}$ \\
\hline OR = operating room & \\
$\begin{array}{l}\text { Table 3. Description of Error Types and Overall } \\
\text { Frequency of Errors }\end{array}$
\end{tabular}

\begin{tabular}{llc}
$\begin{array}{l}\text { Data Collection } \\
\text { Key }\end{array}$ & \multicolumn{1}{c}{ Description } & $\begin{array}{c}\text { No. of } \\
\text { Errors }\end{array}$ \\
\hline $\mathrm{Ml}$ & Missing medication & 41 \\
$\mathrm{OP}$ & Opened or used medication & 9 \\
$\mathrm{OV}$ & Overage & 1 \\
$\mathrm{EX}$ & Expired medication & 5 \\
\hline
\end{tabular}


Table 4. Specific Errors Planted, by Tray Type

\begin{tabular}{|c|c|c|c|c|}
\hline \multirow[b]{2}{*}{ Tray Type } & \multicolumn{4}{|c|}{ Medication Error Category; Specific Errors Planted in Tray* } \\
\hline & Missing & Opened or Used & Overage & Expired \\
\hline \multicolumn{5}{|l|}{ Medium } \\
\hline \multirow[t]{2}{*}{ Resuscitation C (25 items) } & $\begin{array}{l}\text { EPINEPHrine } \\
1 \mathrm{mg} / 10 \mathrm{~mL}(3)\end{array}$ & None & None & None \\
\hline & $\begin{array}{l}2 \% \text { lidocaine } \\
\text { adenosine }\end{array}$ & & & \\
\hline \multirow[t]{2}{*}{ Resuscitation P (47 items) } & $\begin{array}{l}8.4 \% \text { sodium } \\
\text { bicarbonate }\end{array}$ & None & $\begin{array}{l}4.2 \% \text { sodium } \\
\text { bicarbonate }\end{array}$ & $\begin{array}{l}0.9 \% \text { sodium } \\
\text { chloride }\end{array}$ \\
\hline & $\begin{array}{l}\text { 1-mL EPINEPHrine } \\
\text { ampule (2) }\end{array}$ & & & \\
\hline \multicolumn{5}{|l|}{ Extra-large } \\
\hline \multirow[t]{4}{*}{ Resuscitation D (78 items) } & amiodarone $50 \mathrm{mg}$ & propofol $10 \mathrm{mg} / \mathrm{mL}$ & None & $\begin{array}{l}0.9 \% \text { sodium } \\
\text { chloride (2) }\end{array}$ \\
\hline & $\begin{array}{l}\text { EPINEPHrine 1:1000 } \\
\text { ampule (2) }\end{array}$ & metoprolol $1 \mathrm{mg}$ & & \\
\hline & $\begin{array}{l}\text { isoproterenol } 0.2 \mathrm{mg} / \mathrm{mL} \\
\text { magnesium sulfate } \\
500 \mathrm{mg} / \mathrm{mL}\end{array}$ & & & \\
\hline & $\begin{array}{l}\text { metoprolol } 1 \mathrm{mg} \\
\text { naloxone } 0.4 \mathrm{mg} / \mathrm{mL}\end{array}$ & & & \\
\hline \multirow[t]{7}{*}{ Anesthesia OR (138 items) } & $\begin{array}{l}\text { propofol } 10 \mathrm{mg} / \mathrm{mL}(2) \\
\text { rocuronium } 10 \mathrm{mg} / \mathrm{mL} \\
\text { sodium chloride } 0.9 \% \\
10 \mathrm{~mL}(4)\end{array}$ & $\begin{array}{l}\text { labetalol } 5 \mathrm{mg} / \mathrm{mL} \\
\text { neostigmine } \\
\text { rocuronium } 10 \mathrm{mg} / \mathrm{mL}\end{array}$ & None & $\begin{array}{l}\text { ceFAZolin } 1 \mathrm{~g} \\
\text { succinylcholine }\end{array}$ \\
\hline & sterile water & esmolol & & \\
\hline & $\begin{array}{l}\text { succinylcholine } \\
\text { ceFAZolin } 1 \mathrm{~g}(2)\end{array}$ & $\begin{array}{l}\text { dexamethasone } \\
\text { atropine }\end{array}$ & & \\
\hline & $\begin{array}{l}\text { dimenhyDRINATE } \\
50 \mathrm{mg}(2)\end{array}$ & nitroglycerin spray & & \\
\hline & ePHEDrine 50 mg (2) & & & \\
\hline & ketorolac 10 mg (5) & & & \\
\hline & $\begin{array}{l}\text { lidocaine 2\% } 20 \mathrm{~mL}(1) \\
\text { ondansetron } 2 \mathrm{mg} \mathrm{(5)}\end{array}$ & & & \\
\hline
\end{tabular}

*Numbers in parentheses indicate multiple errors in the same tray involving the same medication.

(3) remove, add, or change medications on the basis of systemidentified notifications; (4) rescan the replenished tray to confirm accurate restocking; and (5) approve the tray and print the record indicating its contents. After each technician had completed the automated replenishment process for the 4 tray types, a vendor employee recorded the errors missed by the technician (if any) and the time required for each tray, and then reset all of the tray errors for the next technician.

\section{RESULTS}

\section{Accuracy}

For 2 of the 4 participants, errors remained in some trays after manual replenishment and approval (Table 5). Among the 16 manual study tray runs, a total of 6 trays were approved with errors remaining. The number of errors remaining per tray ranged from 1 to 8 items.

With the automated system, errors were completely eliminated for all 16 study tray runs; no errors remained in any of the trays approved by the 4 technicians with automated RFID-based replenishment.

\section{Restocking Time}

In all but 2 cases (both involving the same technician), a time saving was observed when trays were replenished with the automated process (Table 6). For 11 of the 16 study runs, the time saved ranged from about 2 to about $14 \mathrm{~min}$; for 3 runs, less than a minute was saved, and for 2 runs, replenishment took longer with the automated process. The average time saved per run was $4.4 \mathrm{~min}$, for a total of $70 \mathrm{~min}$ overall.

\section{Other Observations}

As an additional study observation, the pharmacy technicians who processed the trays most quickly using the manual method also had the highest error rates. One participant took slightly more time to process 2 of the trays using the automated system, with marked quality improvement (all errors were found and corrected).

\section{DISCUSSION}

This study confirmed that the manual checking method allows for the possibility of human error, whereby an expired, used, or incorrect medication will be left in a tray, with the 


\section{Table 5. Pharmacy Technicians' Detection of Errors with Manual Replenishment}

Tray Type; No. (\%) of Errors Detected or Missed*

\begin{tabular}{|c|c|c|c|c|}
\hline Technician & Resuscitation C (Adult) & Resuscitation P (Pediatric) & Resuscitation D (Adult) & Anesthesia OR \\
\hline $\begin{array}{l}\text { No. of errors } \\
\text { planted }\end{array}$ & 5 & 5 & 11 & 34 \\
\hline PT 1 & Detected: 5 (100) & Detected: 5 (100) & Detected: 11 (100) & Detected: 34 100) \\
\hline PT 2 & Detected: 5 (100) & $\begin{array}{l}\text { Detected: } 3(60) \\
\text { Missed: } 2(40) \\
\text { 1-mL EPINEPHrine 1:1000 } \\
\text { ampule } \times 2(\mathrm{MI})\end{array}$ & $\begin{array}{l}\text { Detected: } 4(36) \\
\text { Missed: } 7 \text { (64) } \\
\text { amiodarone } 50 \mathrm{mg}(\mathrm{Ml}) \\
\text { EPINEPHrine 1:1000 } \\
\text { ampule } \times 2(\mathrm{Ml}) \\
\text { isoproterenol } 0.2 \mathrm{mg} / \mathrm{mL} \\
\text { (MI) magnesium sulfate } \\
500 \mathrm{mg} / \mathrm{mL}(\mathrm{Ml}) \\
\text { propofol } 10 \mathrm{mg} / \mathrm{mL}(\mathrm{OP}) \\
\text { metoprolol } 1 \mathrm{mg}(\mathrm{OP})\end{array}$ & $\begin{array}{l}\text { Detected: } 27(79) \\
\text { Missed: } 7(21) \\
\text { neostigmine (OP) } \\
\text { succinylcholine (MI) } \\
\text { dimenhyDRINATE } \\
50 \text { mg } \times 2 \text { (MI) } \\
\text { dexamethasone (OP) } \\
\text { succinylcholine (EX) } \\
\text { nitroglycerin spray (OP) }\end{array}$ \\
\hline$\overline{\text { PT } 3}$ & Detected: 5 (100) & $\begin{array}{l}\text { Detected: } 4(80) \\
\text { Missed: } 1(20) \\
0.9 \% \text { sodium chloride (EX) }\end{array}$ & $\begin{array}{l}\text { Detected: } 9(82) \\
\text { Missed: } 2(18) \\
0.9 \% \text { sodium } \\
\text { chloride } \times 2(E X)\end{array}$ & $\begin{array}{l}\text { Detected: } 26(76) \\
\text { Missed: } 8 \text { (24) } \\
\text { dimenhyDRINATE } \\
50 \mathrm{mg} \times 2 \text { (MI) } \\
\text { lidocaine } 2 \% 20 \mathrm{~mL}(\mathrm{MI}) \\
\text { dexamethasone (OP) } \\
\text { atropine (OP) } \\
\text { ceFAZolin } 1 \mathrm{~g} \text { (EX) } \\
\text { succinylcholine (EX) } \\
\text { nitroglycerin spray (OP) }\end{array}$ \\
\hline$\overline{\text { PT } 4}$ & Detected: 5 (100) & Detected: 5 (100) & Detected: $11(100)$ & Detected: 34 (100) \\
\hline
\end{tabular}

$\overline{\mathrm{EX}}=$ expired medication, $\mathrm{Ml}=$ medication missing from tray, OP = container opened or used, OV = overage,

$\mathrm{PT}=$ pharmacy technician.

*For planted errors that were missed by the pharmacy technician, the specific errors and their types (EX, MI, OP, or OV)

are also presented. See Table 4 for the complete list of planted errors.

Table 6. Time Savings Realized after Implementation of Automated RFID Tray Management System

\begin{tabular}{|c|c|c|c|c|}
\hline \multirow[b]{2}{*}{ Technician and System } & \multicolumn{4}{|c|}{ Tray Type; Time* } \\
\hline & Resuscitation C (Adult) & Resuscitation P (Pediatrics) & Resuscitation D (Adult) & Anesthesia OR \\
\hline \multicolumn{5}{|l|}{ Pharmacy technician 1} \\
\hline Manual & 0:05:11 & 0:09:28 & $0: 13: 46$ & $0: 11: 34$ \\
\hline Automated RFID system & $0: 02: 15$ & 0:03:06 & $0: 03: 53$ & $0: 07: 54$ \\
\hline Time saved & $0: 02: 56$ & $0: 06: 22$ & 0:09:53 & $0: 03: 40$ \\
\hline \multicolumn{5}{|l|}{ Pharmacy technician 2} \\
\hline Manual & $0: 04: 42$ & 0:08:08 & 0:08:35 & 0:06:04 \\
\hline Automated RFID system & $0: 03: 45$ & $0: 02: 29$ & 0:03:18 & $0: 05: 33$ \\
\hline Time saved & $0: 00: 57$ & $0: 05: 39$ & $0: 05: 17$ & $0: 00: 31$ \\
\hline \multicolumn{5}{|l|}{ Pharmacy technician 3} \\
\hline Manual & $0: 02: 47$ & $0: 05: 20$ & $0: 04: 32$ & $0: 02: 55$ \\
\hline Automated RFID system & $0: 02: 22$ & $0: 02: 49$ & $0: 05: 10$ & $0: 05: 40$ \\
\hline Time saved & $0: 00: 25$ & $0: 02: 31$ & $-0: 00: 38$ & $-0: 02: 45$ \\
\hline \multicolumn{5}{|l|}{ Pharmacy technician 4} \\
\hline Manual & 0:07:39 & $0: 17: 43$ & $0: 16: 34$ & $0: 11: 00$ \\
\hline Automated RFID system & $0: 02: 51$ & 0:03:59 & 0:03:39 & $0: 07: 26$ \\
\hline Time saved & $0: 04: 48$ & $0: 13: 44$ & $0: 12: 55$ & 0:03:34 \\
\hline
\end{tabular}

$\overline{\mathrm{OR}}=$ operating room, RFID = radio frequency identification

*Times are recorded as hours:minutes:seconds. Negative values indicate an increase in time, rather than a saving.

potential for a medication error to reach the patient.

In contrast, the automated RFID-based system was associated with $100 \%$ accuracy. Automation eliminated human error, as well as the distraction and fatigue often observed with manual replenishment and checking; the automated system does not permit the operator to miss or skip any steps in the process. Given the number of trays replenished annually at the hospital (8073), and using the lowest percentage of tray errors missed with the manual method by the pharmacy technician who had the highest overall number of errors missed (pharmacy technician 2: 21\%), it was extrapolated that a minimum of 1695 tray errors would be eradicated with the automated system. 
Table 7. Number of Trays Restocked Weekly and Annually

\begin{tabular}{lcc} 
Tray Type & $\begin{array}{c}\text { Mean No. of } \\
\text { Trays/Week }\end{array}$ & $\begin{array}{c}\text { No. of } \\
\text { Trays/Year }\end{array}$ \\
\hline Medium (21-50 items) & 1.84 & 95.74 \\
Resuscitation C (adult) & 1.53 & 79.56 \\
Resuscitation P (pediatric) & & \\
\hline Extra-large ( $\geq$ 76 items) & 98.00 & 5096.00 \\
Anesthesia OR & 21.00 & 1092.00 \\
General anesthesia, Branson & 28.00 & 1456.00 \\
Labour and delivery & 1.38 & 71.80 \\
Resuscitation D (adult) & 3.50 & 182.00 \\
Endoscopy & $\mathbf{1 5 5 . 2 5}$ & $\mathbf{8 0 7 3 . 1}$ \\
\hline Overall (7 types) &
\end{tabular}

$\overline{\mathrm{OR}}=$ operating room.

Another advantage of the automated system was the saving of staff time. The study showed that an average of 4.4 min was saved for each tray processed. The estimated number of trays processed at the hospital annually is 8073 (Table 7); therefore, the expected time saving is about $592 \mathrm{~h}$, nearly one-third of a full-time employee's total annual work hours. This time saving allowed the pharmacy to expand other services to the OR to enhance patient care.

Additional benefits of the automated system not specifically investigated in this study but observed by hospital staff after implementation include the ability to track the location of medications in the event of a recall. Specifically, a report within the system allows users to review the specific trays in which a recalled medication is located. The system's virtual logbook records the deployment location of each tray throughout the hospital, such that staff are no longer required to search for and manually check each tray to recover recalled items.

The system also has a consumption report that gives managers the ability to track medication usage, to support decreased stocking or elimination of medications that are infrequently or never used, or increased par levels for medications that are used more frequently. This report also allows for "right sizing" of tray inventory, which reduces waste and drug costs.

Inventory reports generated by the system provide pharmacy technicians with quick and accurate monthly inventory checks for soon-to-expire medications. The system also tracks medication expiration dates. Staff can scan an entire medication bin within the system to determine which expiring medication(s) should be removed or rotated to the front of the bin.

From the perspective of staff members, the workstations are ergonomically designed to maximize productivity. The user interface is intuitive and easy-to-use, which facilitates training of new staff.

\section{SIGNIFICANCE FOR PRACTICE}

Medication trays are an important component of a medication distribution system. They are useful for clinicians in the OR and on nursing units, where they are used on the resuscitation cart for emergency treatment. However, medication trays represent one of the few aspects of the pharmacy distribution system that has not benefited from investments in automation. Historically, tray replenishment has been a tedious manual process, prone to errors in terms of both products stocked and the management of expired products. The introduction of RFID technology has had a significant impact on both the accuracy of and time required for preparation of these products at North York General Hospital. The hospital identified 2 companies in the marketplace that could provide an RFID solution to this patient safety concern. The chosen system had 2 main advantages: first, the RFID tags were small and did not interfere with product labelling and clinician workflow when the trays were in use, and second, encoding of the RFID tags occurred after the tags were attached to the product, which eliminated the chance of tagging and coding errors and also allowed for much easier workflow to manage product segregation.

The vendor supported the implementation process by tagging all existing tray medications and having a representative on site for 2 weeks during the implementation. The only additional staffing required during implementation was a part-time technician to confirm and approve the work done by the vendor's staff. Although saving time was not an objective of implementing the system, the study indicated an annual time saving of about one-third of a full-time technician.

References

1. Brennan TA, Leape LL, Laird NM, Hebert L, Localio AR, Lawthers AG, et al. Incidence of adverse events and negligence in hospitalized patients. Results of the Harvard Medical Practice Study I. N Engl J Med. 1991;324(6):370-6.

2. Wilson RM, Runciman WB, Gibberd RW, Harrison BT, Newby L, Hamilton JD. The Quality in Australian Health Care Study. Med J Aust. 1995; 163(9):458-71.

3. Kohn LT, Corrigan JM, Donaldson MS, editors. To err is human— building a safer health system. Washington (DC): National Academy Press; 1999.

4. Jensen LS, Merry AF, Webster CS, Weller J, Larsson L. Evidence-based strategies for preventing drug administration errors during anaesthesia. Anaesthesia. 2004;59(5):493-504.

Edith Rolko, BScPhm, RPh, is Director of Pharmacy Services, North York General Hospital, Toronto, Ontario.

Thomas Chan, BSCPhm, MBA, RPh, is Manager of Pharmacy Systems, North York General Hospital, Toronto, Ontario.

Competing interests: None declared.

Address correspondence to:

Edith Rolko

North York General Hospital

4001 Leslie Street

Toronto ON M2K 1E1

e-mail: Edith.rolko@nygh.on.ca

Funding and study support: MEPS Real-Time provided nonfinancial support by collecting the data analyzed in this study. Otherwise, the study was funded internally. 